\title{
Genetic diversity of Mycobacterium tuberculosis Complex in Jos, Nigeria
}

\author{
Agatha Ani1 , Torbjørn Bruvik², Yetunde Okoh¹, Patricia Agaba3, Oche Agbaji3 , John Idoko³ and Ulf R Dahle*2
}

\begin{abstract}
Background: Nigeria has a high tuberculosis incidence, and genotyping studies of Mycobacterium tuberculosis Complex (MTC) in the country are necessary in order to improve our understanding of the epidemic.

Methods: Isolates of MTC were isolated from cases of pulmonary tuberculosis in Jos, North Central region of Nigeria during 2006-2008. Drug susceptibility test (DST) was performed on 77 of 111 isolates by proportion method on Lowenstein Jensen $(L J)$ slope while genotyping of mycobacterial DNA was performed by spoligotyping. The SpolDB4 database and the model-based program 'spotclust' were used to assign isolates to families, subfamilies and variants.

Results: A total of 111 pulmonary isolates from consecutive tuberculosis patients in the city of Jos, Plateau State, Nigeria were spoligotyped. A total of 84 (76\%) of the isolates belonged to the Latin American Mediterranean (LAM) family. Of these, 78 isolates were assigned to the LAM10 lineage. Among these, 66 exhibited identical spoligopatterns. Drug susceptibility profiles obtained were not consistently associated with any spoligopattern.

Conclusions: The dominance of few M. tuberculosis lineages suggests either a high rate of transmission, frequent import of closely related strains, or a highly conserved genotype. It remains to be confirmed whether the predominance of identical LAM10 represent an outbreak.

Spoligotyping was useful to gain an overall understanding of the local TB epidemic. This study demonstrated that the incidence of TB in Jos, Nigeria may be caused by a few successful M. tuberculosis families, dominated by the LAM10 family.
\end{abstract}

\section{Background}

Nigeria ranks fifth among the world's high-burden countries, with a number of tuberculosis (TB) cases of 450,000 . The TB incidence is at 311/100,000 and the rate of new sputum smear positive disease is approximately 137/100,000 [1].

Published work on the incidence, drug susceptibility, and epidemiology of Mycobacterium tuberculosis Complex (MTC) in Jos and in Nigeria are scarce. The results of the few reported studies did not address epidemiological concerns [2-5]. Supporting data from additional studies are therefore needed to better understand the current epidemic in this area. Nigeria, like most nations of sub Saharan Africa has been rated endemic for TB due to the association of Mycobacterium species with the human immunodeficiency virus (HIV). It has been reported that

* Correspondence: ulf.dahle@fhi.no

2 Division of Infectious Disease Control, Norwegian Institute of Public Health, Oslo, Norway

Full list of author information is available at the end of the article
$30-45 \%$ of HIV positive persons in Nigeria present with active TB at one point or the other [6].

Points of concern include the proportion of patients lost to follow-up, diagnostic delay, low case detection rate and the continuing high prevalence of HIV. The high case rate in many African countries contributed to a rise of the global TB incidence of $1 \%$ in 2003 , despite stable or declining rates in the rest of the world. The incidence in Nigeria however, declined by $1.3 \%$ between 2005 and 2006 [1]. In order to improve our understanding of the $\mathrm{TB}$ epidemic in this high-incidence country, the current study included 111 strains of MTC species isolated from in Jos, Nigeria. For the genetic studies, DNA of all 111 isolates were obtained during three intervals of 20062008. Currently no laboratory in Nigeria offers spoligotyping services. Spoligotyping is a PCR-based fingerprinting method that detects the presence or absence of 43 defined spacers situated between short direct repeat (DR) sequences in the genomes of members of the MTC 
[7]. Important advantages of spoligotyping are that it is cheap, easy to perform and fast. In addition, it has been demonstrated that the results are highly reproducible [8]. Unique to spoligotyping results are tools like the SpolDB4 database [9] and the web-based computer algorithm 'Spotclust' [10] that can be used to assign new isolates to families, subfamilies and variants. The results from local studies can thus be analyzed and compared to the global MTC population. This may help to better understand the world-wide spread of common MTC families and subfamilies. In the current study we describe the diversity of MTC isolates from Jos, Nigeria, based on spoligotyping, and identify the families and subfamilies responsible for the current persistence and spread of TB in this highincidence community.

\section{Methods}

\section{Settings}

Ethical clearance was granted respectively by The Jos University Teaching Hospital and Plateau State Hospital ethical committees. The study was descriptive of a bacterial collection and contained no material of human origin. Personal data were removed from all bacterial cultures to protect the anonymity of the patients. Patient informed consent was therefore not obtained.

\section{Sputum culture and Drug susceptibility test}

Smear positive sputa from (93 new, 16 followup and 2 failed) cases of pulmonary TB were collected when available from the out patient department of 4 different TBtreatment centers in Jos. Specimens were processed for cultures of Mycobacterium species on Lowenstein Jensen (LJ) medium at the Department of Medical Microbiology, University of Jos, Nigeria as described previously [6].

A total of 77 of the 111 isolates that were phenotypically identified as MTC as previously described [5], were tested for drug susceptibility by the proportion method on LJ medium using $0.2 \mu \mathrm{g}$ isoniazid (INH), $2 \mu \mathrm{g}$ ethambutol (EMB), $40 \mu \mathrm{g}$ rifampicin (RIF) and $4 \mu \mathrm{g}$ streptomycin STR) [5].

\section{Spoligotyping}

Cultures were heat inactivated at $80^{\circ}$ for 20 minutes. A total of 111 heat-killed MTC strains were sent to the National Reference Laboratory for Mycobacteria at the Norwegian Institute of Public Health (NIPH). Upon arrival, DNA was extracted and spoligotyping performed as described elsewhere [7].

DNA was extracted and spoligotyping was performed according to Kamerbeek et al. [7]. A single linkage dendrogram was produced by use of the Bionumerics, version 5.1 software (Applied Maths, Kortrijk, Belgium).

\section{Family assignment}

The obtained spoligopatterns were first compared to the SpolDB4 database and assigned to families and subfamilies [9]. Second, in order to assign names to the isolates not found in the SpolDB4 database, the spoligopatterns were analyzed with 'Spotclust', using a mixture model built on the SpolDB3 database [10]. This model takes into account knowledge of the evolution of the DR region and assigns spoligopatterns to families and subfamilies. The rate of diversity was calculated by dividing the number of spoligotypes by the number of isolates.

\section{Results}

\section{Genetic diversity and family assignment}

The 111 analyzed isolates gave 29 different spoligopatterns resulting in an overall diversity (number of spoligotypes divided by the number of isolates) of 27. A total of 17 spoligopatterns occurred only once and 1 pattern comprised $65 \%$ of the isolates (Figure 1). All patterns had been described previously [9]. Family assignment by use of the SpolDB4 database and 'Spotclust' showed that 84 (76\%) of the isolates belonged to the Latin American Mediterranean (LAM) family, 79 (93\%) of these belonged to the LAM 10 family. A total of 10 (9\%) of the isolates were assigned to the Haarlem family, $6(5 \%)$ to the $\mathrm{X}$ family, $4(4 \%)$ to the T family, $4(4 \%)$ to the F family, and 2 (2\%) to the EAI family. One isolate was assigned to $M$. africanum. The low spoligotype diversity within the MTC population was confirmed by construction of a dendrogram. Most isolates demonstrated more than $90 \%$ homology, and only 6 isolates were less than $80 \%$ homologous to the other strains (Figure 1). The LAM10 clearly dominated the TB epidemic in Jos.

The abundance of the LAM family in this area may indicate that the family is either well adapted to spread, highly conserved, or recently transmitted within this community. The observation of only one isolate of $M$. africanum was unexpectedly low, as previous studies have demonstrated that approximately $13 \%$ of $\mathrm{TB}$ in humans in Ibadan, Nigeria was caused by $M$. africanum type I and M. bovis $[2,3]$.

Drug susceptibility tests were available from 77/111 isolates in this study. A total of 31 strains were resistant to at least one drug, and 19 strains were multidrug resistant (resistant to at least rifampicin and isoniazid) (MDR) strains (Table 1). Although the numbers were low, it was noted that $16 / 56$ tested LAM10 isolates were MDR and 3/4 tested Haarlem-family isolates were MDR.

\section{Discussion}

This study demonstrated that LAM10 isolates were abundant in the current population of MTC isolates from Jos, 


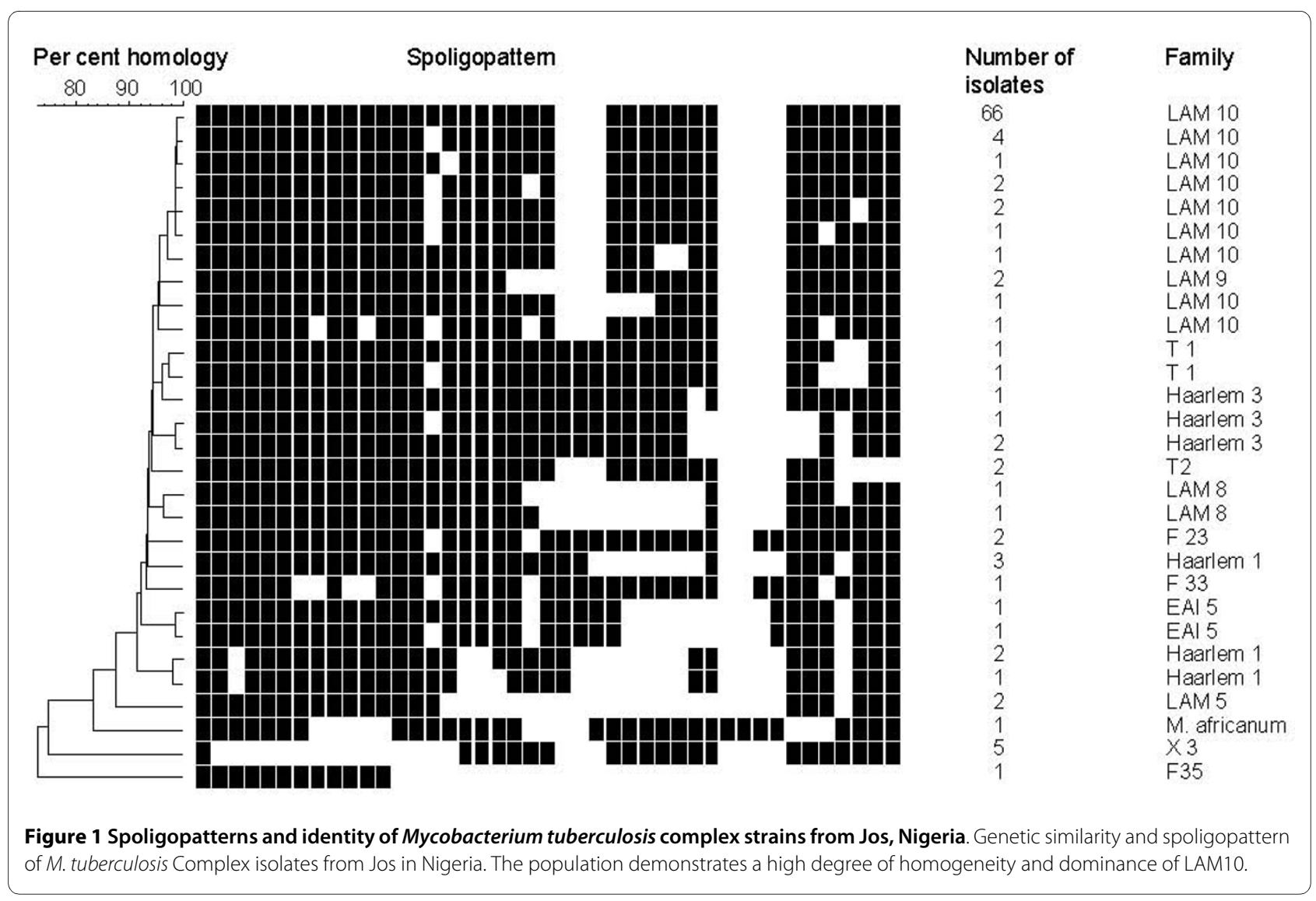

Nigeria. A study conducted in the West province of Cameroon found that 193 of $413 \mathrm{M}$. tuberculosis isolates belong to the Cameroon family (LAM10-CAM) [11], and in Harare, Zimbabwe, 68 of 214 isolates are LAM11-ZWE variants [12]. In Dar Es Salaam, Tanzania however, the overall genetic diversity was calculated at 52 and only 3 of 147 isolates were LAM 10 strains [13]. Of the 111 isolates in this study, 78 were LAM10 and no LAM11 isolates were observed. Although other lineages are found in other countries, these findings indicate that various LAM sub-families dominate in various regions of Africa and that TB epidemics are multiple and local. Other lineages that are abundant in other African countries (such as the LAM11) were absent in the current study. Thus, the MTC populations in high-incidence countries may vary greatly and can be difficult to estimate without molecular epidemiological studies.

The success of the LAM family in particular in this community is intriguing. The highly prevalent LAM10 family in this study may indicate that the family is spreading rapidly, but could also reflect a slow evolution of the DR region. However, one limitation of the current study is related to the uncertainty about the accurate representation of MTC population of Jos, Nigeria. Also, the lack of the more discriminatory methods such as, IS6110 RFLP and MIRU-VNTR typing [14-16], prevents more conclusive results.

The predominance of the LAM family in South America and West-Africa suggests a possible co-evolution between specific MTC families and host populations $[9,17]$. The molecular basis of this theory remains to be elucidated but this pattern might reflect the last centuries' transport and interaction between these continents and the genetic relatedness between Western Africa and the Americas.

The rates of drug susceptibility to first line anti tuberculosis drugs were evenly distributed among the genetic lineages in the current study (Table 1). This may indicate strain-strain heterogeneity or other factors which could not be explained within the scope of this study. Genetic fingerprinting methods with higher discriminatory tendencies are required for better interpretation of the results.

\section{Conclusions}

Spoligotyping performed in this study was useful with insights on the local TB epidemic in Jos, Nigeria. This study demonstrated that the extensive TB epidemic in this area was caused by one successful M. tuberculosis family, dominated by the LAM10 subfamily. Import of 
Table 1: Spoligotypes and drug susceptibility patterns of Mycobacterium tuberculosis from Jos, Nigeria.

\begin{tabular}{|c|c|c|c|c|c|c|c|c|}
\hline & \multirow[t]{2}{*}{ No. of isolates } & \multicolumn{7}{|c|}{ Assignment of Mycobacterium tuberculosis complex isolates } \\
\hline & & LAM 10 & LAM & $\mathbf{H}$ & $\mathbf{X}$ & $\mathbf{T}, \mathbf{F}$ & EAI & M. africanum \\
\hline Total & 111 & $\begin{array}{l}79 \\
(71 \%)\end{array}$ & $\begin{array}{l}5 \\
(4 \%)\end{array}$ & $\begin{array}{l}10 \\
(9 \%)\end{array}$ & $\begin{array}{l}6 \\
(5 \%)\end{array}$ & $\begin{array}{l}4,4 \\
(4 \%, 4 \%)\end{array}$ & $\begin{array}{l}2 \\
(2 \%)\end{array}$ & $\begin{array}{l}1 \\
(1 \%)\end{array}$ \\
\hline DST & 77 & 56 & 4 & 4 & 4 & 4,3 & 1 & 1 \\
\hline PS & 46 & 31 & 3 & 2 & 2 & 4,3 & 0 & 1 \\
\hline MDR & 8 & 8 & 0 & 0 & 0 & 0,0 & 0 & 0 \\
\hline MDR+ & 11 & 8 & 1 & 2 & 0 & 0,0 & 0 & 0 \\
\hline Other & 12 & 9 & 0 & 0 & 2 & 0,0 & 1 & 0 \\
\hline
\end{tabular}

Abbreviations: DST: Drug susceptibility test-results available, PS: Pan susceptible, MDR: Multidrug resistant, MDR+: MDR isolates with additional resistance, other: isolates resistant to drugs but sensitive to either rifampicin or isoniazid.

new strains from neighboring countries appears to represent a minor problem, but such interpretation need confirmation. The spread of TB in this area may however be locally restricted.

\section{Competing interests}

The authors declare that they have no competing interests.

\section{Authors' contributions}

AA contributed to conception and design of the study, laboratory work and data analysis. TB, YO, PA, and OA participated in the clinical evaluation of the patients work and data analyses. Jl participated in the design of the study and the data analyses. UD conceived the study, supervised and participated in the laboratory work and data analyses. All authors contributed in the writing of the article, read and approved the final manuscript.

\section{Acknowledgements}

This work was funded by the University of Jos and The Norwegian Institute of Public Health. The authors would like to thank the personnel that participated in the isolation of MTC

\section{Author Details}

'Department of Medical Microbiology, Faculty of Medical Sciences, University of Jos, Nigeria, 2Division of Infectious Disease Control, Norwegian Institute of Public Health, Oslo, Norway and ${ }^{3}$ AIDS prevention initiative in Nigeria, Centre Jos University Teaching Hospital, Jos, Nigeria

Received: 4 December 2009 Accepted: 26 June 2010

Published: 26 June 2010

\section{References}

1. World Health Organization: Global tuberculosis control - surveillance, planning, financing. WHO report 20082009.

2. Cadmus S, Palmer S, Okker M, Dale J, Gover K, Smith N, Jahans K, Hewinson RG, Gordon SV: Molecular Analysis of Human and Bovine Tubercle Bacilli from a Local Setting in Nigeria. J Clin Microbiol 2006 44:29-34.

3. Cadmus SIB, Jenkins AO, Godfroid J, Osinusi K, Adewole IF, Murphy RL, Taiwo BO: Mycobacterium tuberculosis and Mycobacterium africanum in stools from children attending an immunization clinic in Ibadan, Nigeria. International Journal of Infectious Diseases 2009, 13:740-744.

4. Kehinde AO, Obaseki FA, Ishola OC, Ibrahim KD: Multidrug resistance to Mycobacterium tuberculosis in a tertiary hospital. Journal of the National Medical Association 2007, 99:1185-1189.

5. Ani AE, Idoko J, Dalyop YB, Pitmang SL: Drug resistance profile of Mycobacterium tuberculosis isolates from pulmonary tuberculosis patients in Jos, Nigeria. Transactions of the Royal Society of Tropical Medicine and Hygiene 2009, 103:67-71.

6. Ani A, Okpe S, Akambi M, Ejelionu E, Yakubu B, Owolodun O, Ekeh P, Oche A, Tyen D, Idoko J: Comparison of a DNA based PCR method with conventional methods for the detection of M. tuberculosis in Jos, Nigeria. The Journal of Infection in Developing Countries 2009, 3:470-475.

7. Kamerbeek J, Schouls L, Kolk A, van Agterveld M, van Soolingen D, Kuijper S, Bunschoten A, Molhuizen H, Shaw R, Goyal M: Simultaneous detection and strain differentiation of Mycobacterium tuberculosis for diagnosis and epidemiology. J Clin Microbiol 1997, 35:907-914.

8. Kremer K, van Soolingen D, Frothingham R, Haas WH, Hermans PWM, Martin C, Palittapongarnpim P, Plikaytis BB, Riley LW, Yakrus MA, Musser $J M$, van Embden JDA: Comparison of Methods Based on Different Molecular Epidemiological Markers for Typing of Mycobacterium tuberculosis Complex Strains: Interlaboratory Study of Discriminatory Power and Reproducibility. J Clin Microbiol 1999, 37:2607-2618.

9. Brudey K, Driscoll J, Rigouts L, Prodinger W, Gori A, Al-Hajoj S, Allix C, Aristimuno L, Arora J, Baumanis V, Binder L, Cafrune P, Cataldi A, Cheong S, Diel R, Ellermeier C, Evans J, Fauville-Dufaux M, Ferdinand S, de Viedma D, Garzelli C, Gazzola L, Gomes H, Guttierez MC, Hawkey P, van Helden P, Kadival G, Kreiswirth B, Kremer K, et al:: Mycobacterium tuberculosis complex genetic diversity: mining the fourth international spoligotyping database (SpolDB4) for classification, population genetics and epidemiology. BMC Microbiology 2006, 6:23.

10. Vitol I, Driscoll J, Kurepina N, Kreiswirth B, Bennett K: SpotClust: a tool to cluster spoligotype data for tuberculosis evolution and epidemiology. Recomb Cambrdige, Ma 2005. May 14-18 2005

11. Niobe-Eyangoh SN, Kuaban C, Sorlin P, Cunin P, Thonnon J, Sola C, Rastogi N, Vincent V, Gutierrez MC: Genetic biodiversity of Mycobacterium tuberculosis complex strains from patients with pulmonary tuberculosis in Cameroon. J Clin Microbiol 2003, 41:2547-2553.

12. Easterbrook PJ, Gibson A, Murad S, Lamprecht D, Ives N, Ferguson A, Lowe $\mathrm{O}$, Mason P, Ndudzo A, Taziwa A: High rates of clustering of strains causing tuberculosis in Harare, Zimbabwe: a molecular epidemiological study. J Clin Microbiol 2004, 42:4536-4544. 
13. Eldholm V, Matee M, Mfinanga S, Heun M, Dahle U: A first insight into the genetic diversity of Mycobacterium tuberculosis in Dar es Salaam, Tanzania, assessed by spoligotyping. BMC Microbiology 2006, 6:76.

14. Kinander W, Bruvik T, Dahle UR: Dominant Mycobacterium tuberculosis Lineages in Elderly Patients Born in Norway. PLOS ONE 2009, 4:e8373.

15. Dahle UR, Eldholm V, Winje BA, Mannsaker T, Heldal E: Impact of Immigration on the Molecular Epidemiology of Mycobacterium tuberculosis in a Low-Incidence Country. Am J Respir Crit Care Med 2007, 176:930-935.

16. Abadia E, Sequera M, Ortega D, Mendez M, Escalona A, Da Mata O, Izarra E, Rojas Y, Jaspe R, Motiwala A, Alland D, de Waard J, Takiff H:

Mycobacterium tuberculosis ecology in Venezuela: epidemiologic correlates of common spoligotypes and a large clonal cluster defined by MIRU-VNTR-24. BMC Infectious Diseases 2009, 9:122.

17. Parwati I, van Crevel $R$, van Soolingen D: Possible underlying mechanisms for successful emergence of the Mycobacterium tuberculosis Beijing genotype strains. The Lancet Infectious Diseases 2010, 10:103-111.

Pre-publication history

The pre-publication history for this paper can be accessed here: http://www.biomedcentral.com/1471-2334/10/189/prepub

doi: 10.1186/1471-2334-10-189

Cite this article as: Ani et al., Genetic diversity of Mycobacterium tuberculosis Complex in Jos, Nigeria BMC Infectious Diseases 2010, 10:189

Submit your next manuscript to BioMed Central and take full advantage of:

- Convenient online submission

- Thorough peer review

- No space constraints or color figure charges

- Immediate publication on acceptance

- Inclusion in PubMed, CAS, Scopus and Google Scholar

- Research which is freely available for redistribution

Submit your manuscript at www.biomedcentral.com/submit
C) Biomed Central 